\title{
Influence of Impact Conditions on Feedstock Deposition Behavior of Cold-Sprayed Fe-Based Metallic Glass
}

\author{
Constance W. Ziemian ${ }^{1}$ Wendelin J. Wright ${ }^{1,2} \cdot$ David E. Cipoletti ${ }^{1,3}$
}

Submitted: 11 February 2018/in revised form: 23 March 2018/Published online: 1 May 2018

(c) The Author(s) 2018

\begin{abstract}
Cold spray is a promising method by which to deposit dense Fe-based metallic glass coatings on conventional metal substrates. Relatively low process temperatures offer the potential to prevent the crystallization of amorphous feedstock powders while still providing adequate particle softening for bonding and coating formation. In this study, $\mathrm{Fe}_{48} \mathrm{Mo}_{14} \mathrm{Cr}_{15} \mathrm{Y}_{2} \mathrm{C}_{15} \mathrm{~B}_{6}$ powder was sprayed onto a mild steel substrate, using a variety of process conditions, to investigate the feasibility of forming wellbonded amorphous Fe-based coatings. Particle splat adhesion was examined relative to impact conditions, and the limiting values of temperature and velocity associated with successful softening and adhesion were empirically established. Variability of particle sizes, impact temperatures, and impact velocities resulted in splat morphologies ranging from well-adhered deformed particles to substrate craters formed by rebounded particles and a variety of particle/substrate interface conditions. Transmission electron microscopy studies revealed the presence of a thin oxide layer between well-adhered particles and the substrate, suggesting that bonding is feasible even with an increased oxygen content at the interface. Results indicate that the proper optimization of cold spray process parameters supports the formation of Fe-based metallic glass coatings that successfully retain their amorphous structure,
\end{abstract}

Constance W. Ziemian

cziemian@bucknell.edu

1 Department of Mechanical Engineering, Bucknell University, Lewisburg, PA 17837, USA

2 Department of Chemical Engineering, Bucknell University, Lewisburg, PA 17837, USA

3 Present Address: Hydro Flask, 525 NW York Dr, Bend, OR 97703, USA as well as the superior corrosion and wear-resistant properties of the feedstock powder.

Keywords bulk metallic glass (BMG) alloy · cold spray deposition behavior $\cdot$ splat morphology

\section{Introduction}

Iron $(\mathrm{Fe})$-based amorphous alloys are recognized as important engineering materials due to their high strength and hardness, superior wear and corrosion resistance, and excellent soft magnetic properties, in addition to their relatively low cost $(\operatorname{Ref} 1,2)$. In addition, researchers have been successfully establishing compositions of glassy iron alloys that will retain an amorphous microstructure under significantly lower cooling rates than early melt-spun alloys (Ref 3). At this time, iron-based bulk metallic glasses with critical cooling rates as low as on the order of $100 \mathrm{~K} / \mathrm{s}$ have been found in Fe-based alloy systems containing metalloids (B, C, Si, and P) (Ref 4). However, their use as structural materials has been hindered by their generally low ductility and the difficulties associated with obtaining cooling rates high enough to produce large gauge glassy material. As a result, alternate material systems by which to exploit the superior properties of these amorphous alloys continue to be explored, including their use as thick corrosion and wear-resistant layers on top of crystalline metal substrates. This study is motivated by the goal of forming such material systems, including a fully amorphous Fe-based metallic glass coating on a mild steel substrate, in order to widen the assortment of their feasible industrial applications.

Much work has been done toward producing amorphous coatings using conventional deposition and thermal spray 
methods, but the majority of it has only achieved partial success due to the occurrence of oxidation during processing that provides nucleation sites (Ref 5-11). In many cases, the coatings are thin $(\sim 100 \mu \mathrm{m}$ thick) and do not maintain a purely amorphous structure, having face-centered cubic Fe-based dendrites and fine crystalline precipitates within an amorphous matrix. The cold spray process is a novel alternative for producing dense coatings through an impaction process based on the acceleration of metallic powder particles toward a substrate. The feedstock powder particles travel at high velocities in an unreactive gas, such as nitrogen, and collide with the substrate such that their kinetic energy promotes coating formation by plastic deformation (Ref 12). As a solid-state process, cold spray can utilize temperatures that are consistently lower than the melting point of the powder material (Ref 13). As a result, successful cold-sprayed coatings typically do not demonstrate oxidation or residual stresses and are free from the phase transformations, microstructural changes, and grain growth that occurs in thermal spray processes that involve melting (Ref 12).

At this time, numerous conventional metals and alloys have been successfully synthesized as cold-sprayed coatings without oxidation or phase transformation, and characterized on the basis of various mechanical properties and corrosion resistance (Ref 14-18). An understanding of the effectiveness of cold spray for producing coatings from amorphous feedstock powders, however, is far less developed. The balance of particle impact temperatures and velocities is complicated by the brittleness of metallic glasses at ambient temperature (Ref 19), making it less clear if shear instabilities at the particle or substrate surfaces will cause the necessary local softening for the formation of strong and intimate interface bonding. The criteria for cold spray bonding require detailed study and the development of in-depth understanding of the plastic flow of these amorphous powders at very high strain rates.

Studies have shown that successful bonding of coldsprayed powder can only be achieved when impacting particles reach a minimum critical velocity, which depends on powder and substrate properties (Ref 20, 21). The plastic deformation of feedstock particles is often insufficient to achieve bonding when their impact velocity is below the critical value. There is also experimental evidence that higher impact velocity does not always correlate with a larger fraction of adhered particles (Ref 22). This is due to a rebound phenomenon that typically occurs when particles either fail to reach the critical velocity or exceed the upper limit of impact velocity, known as the erosion velocity. In addition, when the velocity exceeds the erosion value, hydrodynamic penetration leads to strong erosion rather than bonding. These observations suggest that successful cold-sprayed particle adhesion is feasible when impact velocities fall within the two velocity limits (critical and erosion), and particle impact temperatures are favorable for deformation and bonding. This concept of a deposition window was introduced by Schmidt et al. (Ref 20) and previously developed for the cold spray of crystalline feedstock powder.

The current study investigates the critical velocity for cold-sprayed Fe-based amorphous powder $\mathrm{Fe}_{48} \mathrm{Mo}_{14} \mathrm{Cr}_{15}$ $\mathrm{Y}_{2} \mathrm{C}_{15} \mathrm{~B}_{6}$, (known as SAM1651) using individual particle impact (splat) tests. Splat tests are also used to study the onset of coating deposition as they allow for the observation of the behavior of individual feedstock particles (Ref 15). The developed temperature analysis accounts for the fact that amorphous metals do not behave in the same manner as crystalline materials with regard to thermal softening and impact mechanics. The critical conditions for particle adhesion are calculated on the basis of the experimentally determined hardness of amorphous SAM1651, the mass density $(\rho)$ of the alloy, and an empirically defined softening temperature. The window of favorable impact conditions is validated using splat test results and detailed analysis of particle adhesion. Splat morphologies are characterized to study coating deposition onset and explore the cold spray feasibility of this Fe-based amorphous alloy, including consideration of optimal process parameters. The study contributes to the understanding of underlying mechanisms associated with the cold spray deposition of metallic glass powder. This is expected to advance efforts to form fully amorphous coatings on crystalline metal substrates and thereby expand the list of potential industrial applications that will benefit from the superior properties of metallic glasses.

\section{Experimental Procedure}

\section{Feedstock Powder Characterization}

Amorphous $\mathrm{Fe}_{48} \mathrm{Cr}_{15} \mathrm{Mo}_{14} \mathrm{C}_{15} \mathrm{~B}_{6} \mathrm{Y}_{2}$ (at.\%), or SAM1651, was selected for this study due to its superior corrosion resistance and high hardness (Ref 23). The SAM1651 powder was commercially manufactured (Carpenter Powder Products, Pittsburgh, PA) by inert gas atomization and sieved to a target size range of 10-40 $\mu \mathrm{m}$. Characterization of the feedstock powder was conducted using laser diffraction (Malvern Mastersizer, Malvern Instruments Inc., Westborough, MA) to verify the particle size distribution, X-ray diffraction (XRD) (PANalytical X'Pert Pro MPD, PANalytical, Almelo, Netherlands) to assess the crystallinity of the initial powder, and scanning electron microscopy (SEM) (JEOL JSM 500-type, JEOL, Inc., Peabody, MA) to inspect the initial powder morphology. Characteristic temperatures were determined by 
differential scanning calorimetry (DSC) (TA Instruments Q2000 MDSC, New Castle, DE) and differential thermal analysis (DTA) (TA Instruments Q600 STD, New Castle, DE).

\section{Cold Spray Splat Tests}

A commercial Plasma Giken cold spray system (PCS-304, at Mid-America Aviation, Webster, MA), with a maximum operating temperature of $1000{ }^{\circ} \mathrm{C}$, was used to spray SAM1651 powder onto AISI 4140 steel coupons $(25.4 \times 25.4 \mathrm{~mm}) .4140$ steel was selected due to its extensive use in industrial applications and the perceived benefit that a successful coating would improve its limited corrosion resistance. Prior to spray adhesion testing, the steel coupons were polished to a mirror-like finish $(R a<1.5 \mu \mathrm{m})$.

The spray gun traverse speed across the substrate and the particle feed rate were adjusted to $200 \mathrm{~mm} / \mathrm{s}$ and $0.25 \mathrm{rpm}$, respectively, in order to limit the amount of powder impacting the substrate and ensure the deposition of single-particle splats. All tests were performed using a de Laval nozzle with entrance, throat, and exit diameters of 15,3 , and $6.5 \mathrm{~mm}$, respectively, and converging and diverging lengths of 77 and $183 \mathrm{~mm}$ (Fig. 1). The steel substrate was held at ambient temperature at a standoff distance of $40 \mathrm{~mm}$ from the nozzle exit.

Powder particles were preheated while passing through a 90-mm-long pre-chamber, together with the nitrogen carrier gas, prior to entering the nozzle. Splat tests were all conducted with gas pressure held constant at $4 \mathrm{MPa}$. Gas temperatures, in contrast, were systematically varied, so each run was completed at $850,900,950$, or $1000{ }^{\circ} \mathrm{C}$. The variation of gas temperature and the assortment of powder particle sizes resulted in a wide range of particle impact temperatures and velocities, as predicted by the developed computational model.

\section{Computational Modeling}

In order to optimize the cold spray process for the deposition of metallic glass powder particles, the effects of process parameters on particle impact conditions are

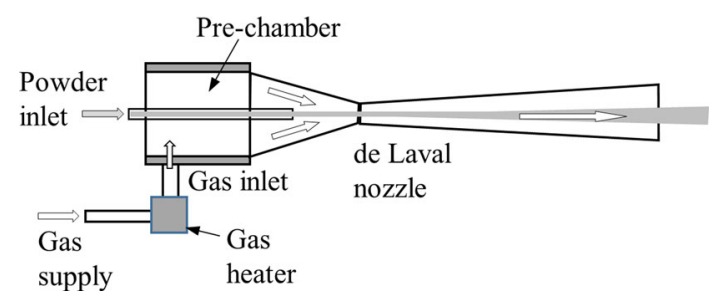

Fig. 1 Schematic of cold spray pre-chamber and nozzle needed. This information is then utilized to compute the kinetic and thermal energies of the particles just prior to substrate collision and to investigate cold spray adhesion, rebounding, and deposition efficiency. The accurate experimental measurement of particle temperatures and velocities at impact is difficult, however, due to the high speed and small size of the particles and the fact that their paths and locations in the gas stream affect their velocities. Experimental isolation of a specific particle at a defined location in the powder stream is also very difficult to achieve with accuracy. For these reasons, models have been developed to predict the impact conditions of coldsprayed powder particles.

An analytical model based on one-dimensional, isentropic, gas-dynamic equations of particle flow in a fluid stream was previously developed by Champagne et al. (Ref $24,25)$ and is presented in the literature together with experimental validation data. While the agreement between experimentally measured impact conditions and those predicted using the analytical model is reasonable, there are differences between them that are attributed to frictional effects and particle distribution within the stream. These effects, as well as the detailed particle behavior between the nozzle exit and the substrate surface in general, can be more accurately predicted with a computational fluid dynamic (CFD) model. For this study, a CFD model with the ability to parse the impact conditions of individual particles in specific locations within the nonuniform stream was developed to predict the gas and particle temperatures and velocities.

ANSYS ${ }^{\circledR}$ Fluent (Ref 26) was used to model the influences of nozzle geometry and significant process parameters, such as process gas, gas temperature and pressure, spray material type, and particle size, on particle impact conditions. The system fluid was modeled as nitrogen gas, and the powder particles were represented as a discrete phase using the characteristics of SAM1651 metallic glass. A two-dimensional axisymmetric model was implemented on the basis of the cylindrical nature of the de Laval nozzle and the associated flow through it. Dimensions were set to correspond to the previously described Plasma Giken nozzle, including consideration of a pre-chamber that allows the gas flow to be fully developed upon entering the converging section of the nozzle. The model includes flow exiting the nozzle and impacting a hard, solid wall at the defined standoff distance. The metallic glass particles are absorbed by the substrate; however, the gas is able to rebound from it. The flow is considered to be turbulent and is modeled using the standard k-omega equations (Ref 27). The gas is assumed to be compressible, and the solution was obtained using the density-based version of the Navier-Stokes equations to allow for changing density with Mach number. 
To determine drag, particles were assumed to be spherical and monodisperse. The model defines gas pressure and temperature at the input of the pre-chamber. At the nozzle exit, air is assumed to be at ambient temperature and pressure. The model assumes that the particles have a small input velocity to enter the system; the particle velocity then equilibrates with the gas velocity upon entry to the nozzle. Due to the physical size and thermal properties of the particles, the model predicts that the temperature of the particles reaches the gas temperature by the time they exit the pre-chamber. The fluid velocity stays relatively constant throughout the pre-chamber and starts to increase slightly in the converging section of the nozzle. The velocity increases greatly at the throat as the fluid reaches sonic speed, and further increases to supersonic speeds as the nozzle diverges. After the initial high rate of increase, the velocity continues to increase at a decreasing rate until the nozzle exit is reached. The gas velocity fluctuates after exiting the nozzle due to pressure waves that are created from the fluid rebounding after impact with the substrate.

The impact conditions predicted with this CFD model (Fig. 2) were subsequently compared with those from the aforementioned analytical model (Ref 24), as a means to assess the relative agreement with expected experimental results.

\section{Specimen Inspection and Analysis}

To study the effect of impact velocity and temperature on the adhesion of cold-sprayed metallic glass powder, the cold-sprayed specimens were examined using SEM. Each specimen includes a resulting band of sprayed particles that is approximately $2 \mathrm{~mm}$ wide and spans the full $25.4 \mathrm{~mm}$ length. This band includes multiple splats of different powder particle sizes, representing a variety of impact conditions. SEM inspection was used to count the number of adhered particles and rebound craters within four rectangular areas (each $500 \mu \mathrm{m} \times 500 \mu \mathrm{m}$ ) on each specimen; each area was randomly selected within one of the four

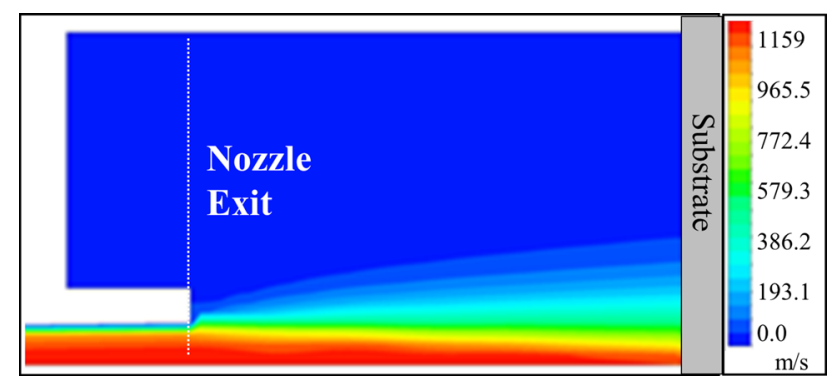

Fig. 2 Top half of the CFD flow contour, depicting velocity after exiting the nozzle and before impacting the substrate at the right (Ref 28) quarters of the $25.4 \mathrm{~mm}$ length. These quantities were then categorized on the basis of particle or crater diameter, using 5 - $\mu \mathrm{m}$-size bins, and the associated impact velocities and temperatures were predicted by the described computational model. The ratio of bonds, defined as the number of adhered particles divided by the total number of impacted particles (craters + bonds) in a unit area of impact surface, was subsequently calculated for each spray condition based on the SEM results. Quantitative results were used to develop an empirical model of critical velocity and a temperature/velocity window of successful particle deposition.

Single-particle splats were also individually examined by SEM and categorized in one of three identified morphology types. Several splats were additionally sectioned using a focused ion beam (FIB) (FEI Quanta 200 3D Dual Beam FIB, Hillsboro, OR) and further studied by SEM in an effort to corroborate the level of perceived deformation and adhesion. Particle/substrate interfaces were also examined using transmission electron microscopy (TEM) (FEI Talos F200X STEM, Hillsboro, OR) in an attempt to characterize the quality of bond formed during cold spray. A layer of carbon was deposited on each particle in order to prevent milling artifacts and damage, and thin foils ( $100 \mathrm{~nm}$ ) were subsequently prepared using a FIB. Each of the foils was examined on the FEI Talos F200X scanning/transmission electron microscope (S/TEM) with a field emission source at $200 \mathrm{kV}$ to investigate local interface phenomena.

\section{Results and Discussion}

\section{Feedstock Powder Properties}

The Fe-based metallic glass powder used in this study presented a unimodal size distribution with a range of 5-45 $\mu \mathrm{m}$, a mean diameter of $19 \mu \mathrm{m}$, and a median diameter $14.1 \mu \mathrm{m}$ (Fig. 3a). XRD analysis of the feedstock powder showed a broad peak typical of an amorphous material (Fig. 3b) as expected. The powder morphology, examined by SEM, revealed the presence of both spherical and irregularly shaped particles (Fig. 3c and d). The thermal properties of the alloy were determined, using DSC and DTA, to include glass transition $\left(T_{\mathrm{g}}\right)$, onset crystallization $\left(T_{\mathrm{x}}\right)$, and melting $\left(T_{\mathrm{m}}\right)$ temperatures of approximately 575,655 , and $1120{ }^{\circ} \mathrm{C}$, respectively. These values are in general agreement with other published works on the properties of SAM1651 (Ref 29).

Nanoindentation was performed at multiple locations on the bulk alloy. Results indicate a mean elastic modulus of $224 \mathrm{GPa}$ and hardness of $15.7 \mathrm{GPa}$. The tensile strength was first estimated using this elastic modulus and applying 


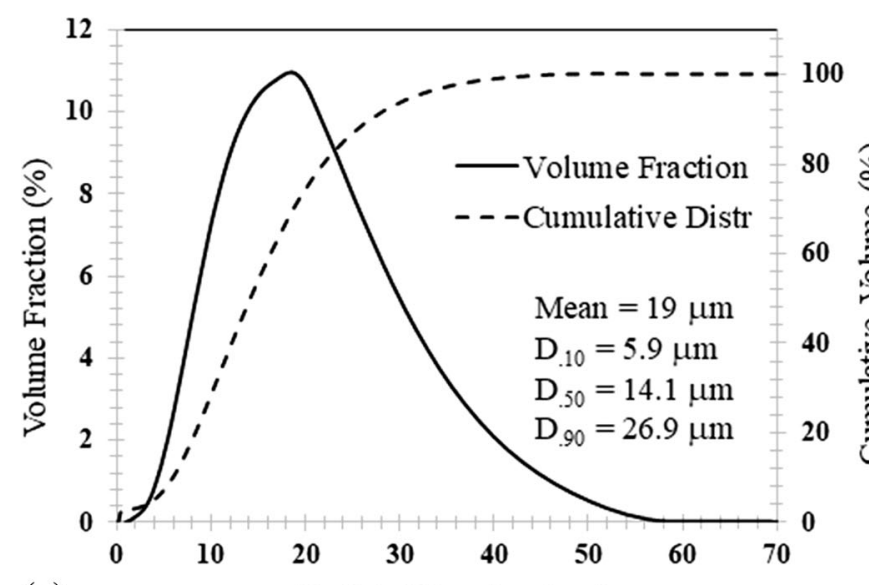

(a)
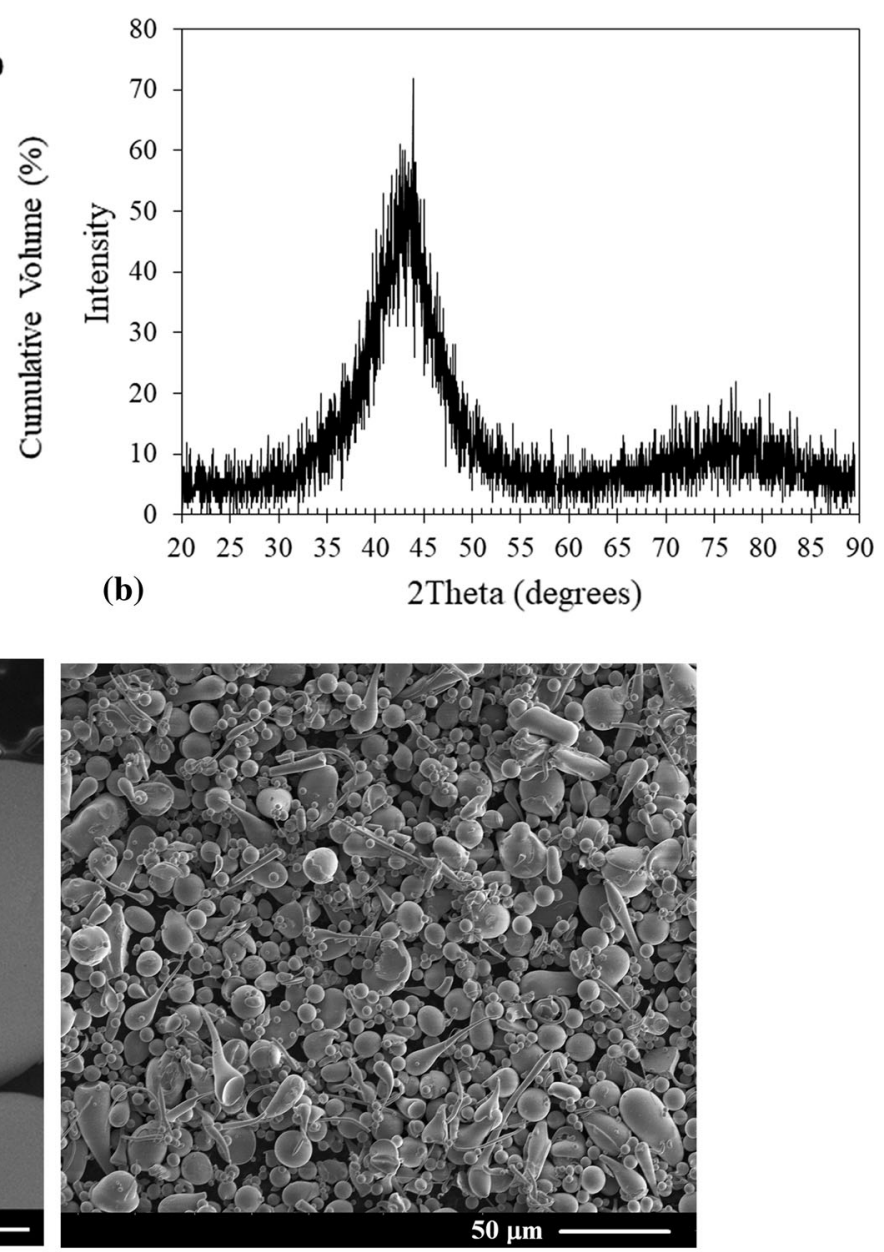

(d)

Fig. 3 Characterization of as-received SAM1651 powder. (a) Particle size distribution; (b) XRD pattern (Ref 30); (c) SEM micrograph of surface morphology; (d) powder morphology

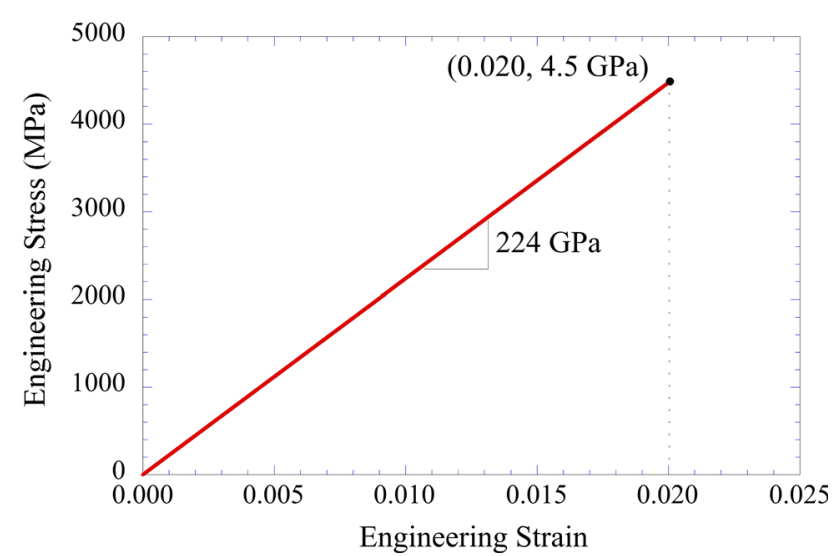

Fig. 4 Compressive stress/strain curve for SAM1651 at a strain rate of $10^{-4} \mathrm{~s}^{-1}$

the assumption that elastic strain at failure is approximately $2 \%$ (Ref 31). The resulting estimate of $4.3 \mathrm{GPa}$ was later confirmed by bulk uniaxial compression testing, which indicates a compressive failure strength of $4.5 \mathrm{GPa}$ as shown in Fig. 4.

\section{Computational Model Validation}

The particle and gas velocity and temperature plots, as functions of position along nozzle length, are displayed in Fig. 5 for both the computational model and an experimentally validated analytical model (Ref 24 ) for comparison. In these plots, the pre-chamber is to the left of the origin, the nozzle throat is at $0.077 \mathrm{~m}$, and the nozzle exit is at $0.260 \mathrm{~m}$. For the illustrative comparison, the input gas has a pressure of $4 \mathrm{MPa}$ and a temperature of $850{ }^{\circ} \mathrm{C}$, and the particle diameter is $20 \mu \mathrm{m}$, which is approximately equal to the mean particle size of the feedstock powder used in the experimental study.

The two models predict similar velocity and temperature trends, but display distinct differences due to their respective underlying assumptions. The computational model shows 


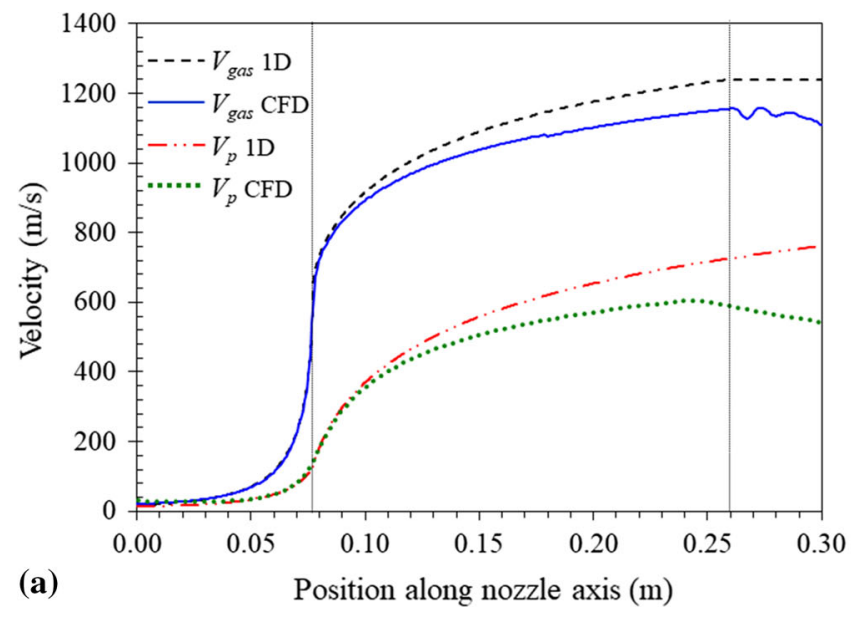

Fig. 5 Velocity and temperature results from computational (CFD) and analytical (1D) models plotted as functions of position along nozzle length, for a $20-\mu \mathrm{m}$ particle. The locations of the nozzle throat

fluctuations in the gas velocity and temperature upon exiting the nozzle due to pressure waves that result from the impact of gas flow against the substrate material. The analytical model does not capture this behavior. The analytical model predicts higher gas and particle velocities than the finite element model, in part due to the assumption that flow is inviscid in the analytical model. The computational model accounts for viscosity, which is small for nitrogen gas, but may be relevant to this discrepancy.

The computational model predictions of temperature also differ from those of the analytical model (Fig. 5b), with the 1D model predicting higher particle temperature and lower gas temperature than the computational model. In both models, the fluid temperature is high at the nozzle entrance, decreases at a rapid rate through the throat, and continues to decrease at a reduced rate as it moves through the diverging section of the nozzle. Upon exiting the nozzle, the pressure waves cause fluctuations in gas temperature. This fluid behavior also affects the metallic glass powder particles within the gas stream, whose velocity and temperature drop at a constant rate upon exiting the nozzle. The differences between the predicted temperatures of the two models are in part due to the way in which the heat transfer between the particles and the fluid is modeled. The analytical model uses a forced convection law, while the computational model uses natural convection and balances the energy equation.

The computational model is used to predict impact conditions in this study, as it better captures the behavior associated with pressure waves and it accounts for viscosity.

\section{Effect of Impact Conditions and Particle Size on Adhesion}

A summary of the experimental particle adhesion data was previously published elsewhere (Ref 28) and is briefly

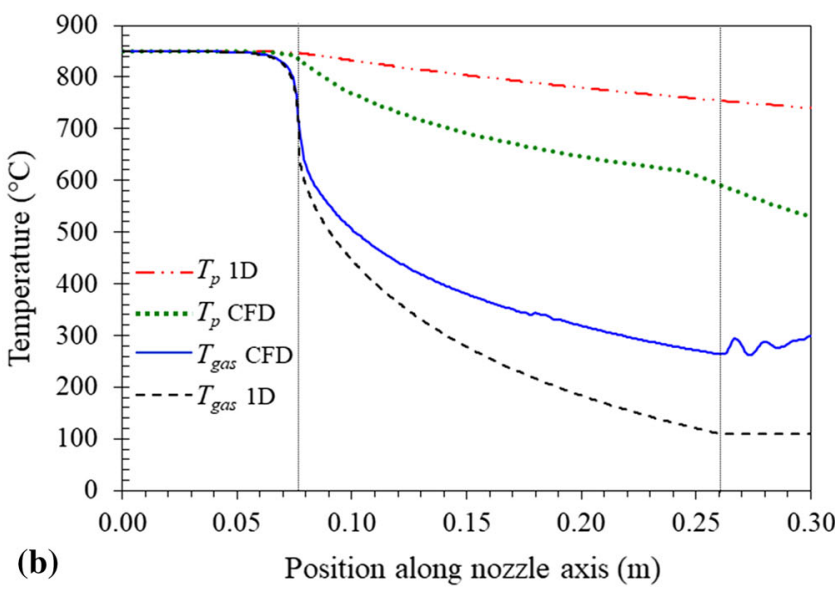

$(0.077 \mathrm{~m})$ and exit $(0.260 \mathrm{~m})$ are identified by vertical lines. (a) Velocity of gas $V_{g}$ and particle $V_{p}$; (b) temperature of gas $T_{\text {gas }}$ and particle $\mathrm{T}_{\mathrm{p}}$

summarized again here. In general, the results indicate that adhesion of cold-sprayed SAM1651 is influenced by both particle size and gas temperature (Fig. 6). The specimens show evidence of a greater number of craters than adhered particles at particle diameters below $5 \mu \mathrm{m}$ and more adhered particles than craters at diameters greater than $10 \mu \mathrm{m}$. With sizes between 5 and $10 \mu \mathrm{m}$, the number of adhered particles was similar to the number of craters, with no obvious dominance of either deposition or particle rebound. These trends are also detectable in SEM micrographs (Fig. 7).

The size effect was further studied with respect to the adhesion results and the velocity and temperature predictions offered by the computational model. The data were consolidated on the basis of particle impact velocities and temperatures, which are significantly affected by particle size (Ref 28). Smaller particles achieve greater velocities within the nozzle due to their low mass, but this low mass also causes them to be more significantly affected by the shock waves produced as the gas flow stream rebounds from the substrate surface. In contrast, the larger particles achieve greater momenta, causing them to be less significantly affected by the shock wave, and thus continue to increase speed slightly from the nozzle exit until impact with the substrate (Ref 25).

Particle size also has an effect on impact temperature. As shown in Fig. 5(b), the gas temperature decreases significantly as it flows to the nozzle exit from the throat. The temperatures of smaller particles decrease more rapidly toward that of the gas, while the greater thermal mass of larger particles renders them less affected by the decrease in gas temperature. Similarly, the use of a pre-chamber is the most important for larger particles as they need more time than that spent in the converging length of the nozzle to reach the gas temperature. Upon exiting the nozzle, 
Fig. 6 Particle adhesion results for gas pressure of $4 \mathrm{MPa}$ and gas temperatures of 850,900 , 950 , and $1000{ }^{\circ} \mathrm{C}(\operatorname{Ref} 28)$. (a) Size distribution of adhered particles; (b) size distribution of rebounded craters. Data are normalized by total impacting particles of each type in sampled region for each specimen. For example, $5 \%$ of the adhered particles deposited at a temperature of $850{ }^{\circ} \mathrm{C}$ have a diameter of $0-4.99 \mu \mathrm{m}$

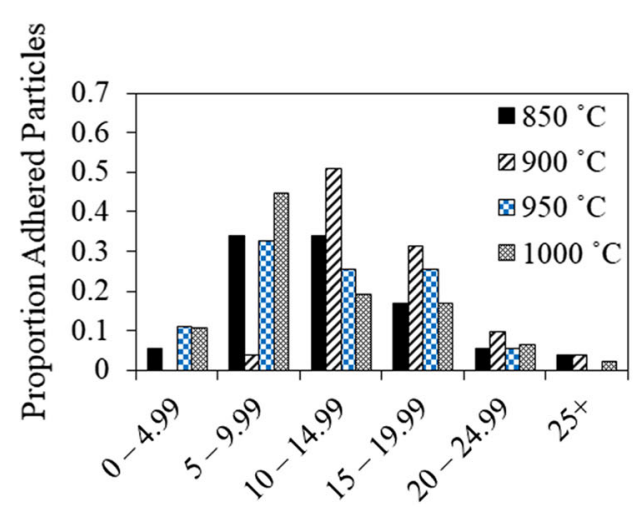

(a) Adhered Particle Size ( $\mu \mathrm{m})$

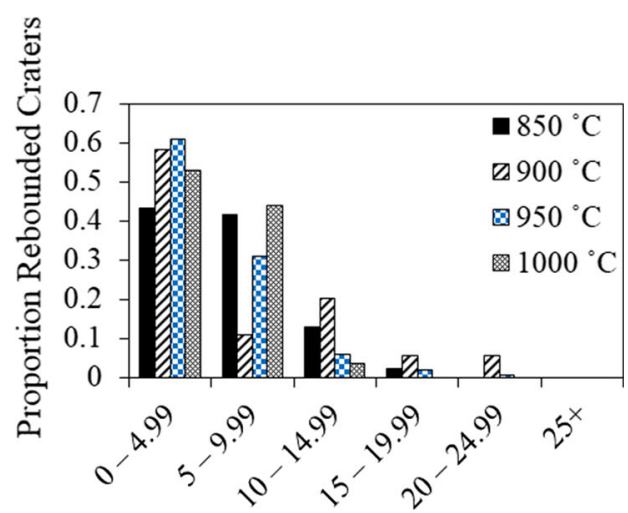

(b) Rebounded Particle Size $(\mu \mathrm{m})$

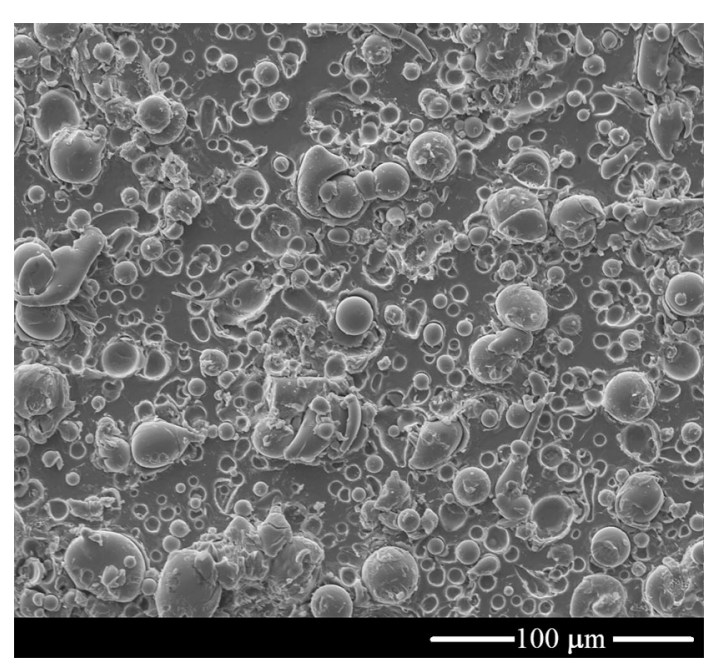

Fig. 7 SEM image of specimen (gas $1000{ }^{\circ} \mathrm{C}, 4 \mathrm{MPa}$ ) revealing adhered particles and rebound craters (Ref 28)

particle temperatures generally increase as they pass through the shock wave. This effect is more significant for smaller particles.

\section{Temperature and Velocity Limits of Successful Deposition}

The critical velocity for cold spray particle adhesion depends on a wide variety of factors, including the properties of feedstock powder and substrate materials, particle size and geometry (Ref 25), particle temperature (Ref 32), particle oxygen content (Ref 33), and substrate preparation (Ref 34, 35). Previous work suggests that the most significant of these factors are the temperature and thermomechanical properties of the sprayed material (Ref 36). In order to achieve successful deposition using cold spray, the powder particles must attain the critical velocity $v_{\mathrm{c}}$ without exceeding the erosion velocity $v_{\mathrm{e}}$ and achieve an impact temperature that permits the material softening.
Schmidt et al.'s deposition window (Ref 20) uses a model that predicts the limiting velocities of crystalline powders on the basis of the interaction between material strength and dynamic load, through the use of the JohnsonCook (Ref 37) equation for thermal softening. Their critical velocity expression is then calibrated using two fitting parameters $\left(F_{1}\right.$ and $\left.F_{2}\right)$, which are adjusted to account for rebounding rather than adhesion when computing erosion velocity. The resulting formula for $v_{\mathrm{c}}$ and $v_{\mathrm{e}}(\mathrm{Eq} 1)$ is a function of the temperature-dependent flow stress $(\sigma)$, density $(\rho)$, heat capacity $\left(c_{\mathrm{p}}\right)$, melting temperature $\left(T_{\mathrm{m}}\right)$, and mean temperature $\left(T_{\mathrm{p}}\right)$ of particles upon impact (Ref 20) according to

$v=\sqrt{\frac{4 F_{1} \sigma}{\rho}+F_{2} c_{\mathrm{p}}\left(T_{\mathrm{m}}-T_{\mathrm{p}}\right)}$

Equation 1 is used to find both $v_{\mathrm{c}}$ and $v_{\mathrm{e}}$ with different fitting parameters $F_{1}$ and $F_{2}$ for each.

The current study uses this same framework as the basis of an investigation of the limiting velocities associated with cold-sprayed amorphous SAM1651. For this feedstock powder, the temperature analysis was altered to account for the fact that amorphous metals do not work harden nor do they behave in the same manner as crystalline materials with regard to thermal softening and impact mechanics. Similarly, the melting temperature $T_{\mathrm{m}}$ is not a reasonable reference temperature for the softening of this alloy (Ref 38). The strain rate- and temperature-dependent yield strength expression was therefore adjusted to eliminate the effect of strain hardening and to include a reference softening temperature $T_{\mathrm{s}}$ that differs from $T_{\mathrm{m}}$. The developed expression for temperature-dependent flow stress is described elsewhere (Ref 28).

Using the computational flow model and the SAM1651 experimental adhesion results, an empirical study was completed to estimate a useful reference temperature for softening $T_{\mathrm{s}}$ and to predict critical impact velocities. To examine the limiting bounds of $T_{\mathrm{s}}$, consideration was first 
given to the case in which $T_{\mathrm{s}}=T_{\mathrm{m}}=1120{ }^{\circ} \mathrm{C}$ is the reference value for softening (Ref 39 ). Using $T_{\mathrm{s}}=T_{\mathrm{m}}$ to calculate the temperature-dependent flow stress and both $v_{\mathrm{c}}$ and $v_{\mathrm{e}}$ (Eq 1), the predicted particle impact conditions, as determined by the computational model for all gas temperatures tested, all fall below the required critical velocity (Fig. 8a). These results predict that no particles will achieve a velocity sufficient to ensure adhesion, which oppose the experimental evidence. If instead, $T_{\mathrm{s}}=T_{\mathrm{g}}$ $=575{ }^{\circ} \mathrm{C}$ is used as a reference value for the softening of Fe-based metallic glass, all of the impact conditions as predicted by the computational model are above the defined erosion velocity (Fig. 8b), which contradicts experimental splat results and corresponds to a condition in which all of the particles would rebound and cause erosion.

Consideration of the limiting cases (Fig. 8) supports the expectation that a more reasonable softening temperature is one that falls between the values of $T_{\mathrm{g}}$ and $T_{\mathrm{m}}$. Using an iterative process to analyze deposition windows associated with different values of $T_{\mathrm{s}}$ for which $T_{\mathrm{g}} \leq T_{\mathrm{s}} \leq T_{\mathrm{m}}$ for SAM1651 (Ref 28), a softening temperature of 1.4 times the glass transition temperature (in degrees Celsius) was determined to best represent the experimental adhesion results. For SAM1651, this temperature is $T_{\mathrm{s}}=1.4$, $T_{\mathrm{g}}=805{ }^{\circ} \mathrm{C}$. The empirical model results associated with this softening temperature (Fig. 9a) form a relatively narrow window of successful particle adhesion relative to the wide range of impact conditions achieved experimentally. The hooked shape of the impact condition curves additionally displays evidence of the size effects and accentuates the dependence of impact conditions, and adhesion, on particle size.

The experimental adhesion results obtained for specimens with $T_{\text {gas }}$ of 900,950 , and $1000{ }^{\circ} \mathrm{C}$ are presented in Fig. 9(b) and appear to suggest the same general trends as those predicted by the model. For example, for a gas temperature of $900{ }^{\circ} \mathrm{C}$, the model predicts the successful deposition of SAM1651 particles with diameters between 14 and $22 \mu \mathrm{m}$ and between 3 and $3.75 \mu \mathrm{m}$. The experimental results for the case of $900{ }^{\circ} \mathrm{C}$ gas indicate the highest proportion of adhered particles were those with diameters between 12 and $23 \mu \mathrm{m}$, with much smaller proportions of adhered particles of other sizes. This is in general agreement with the model, but some amount of error is also present. The empirical model is based on the CFD predictions for particle impact conditions, which include an undefined level of error, and the experimental adhesion results are manually gathered from four sampled regions on each specimen, which include human inspection error and are not based on the entire population of adhered particles of the specimen. As such, the agreement between the model and the experimental results is currently in the context of the limitations of both. More comprehensive CFD model validation and additional experimental results are expected as part of full coating studies.

\section{Characterization of Splat Morphologies}

The adhesion model and experimental validation suggest that the formation of bonds between cold-sprayed metallic glass particles and the steel substrate is influenced by the impacting temperature and velocity of the particle, which depend on the particle size and process parameter settings. More detailed information regarding the particle/substrate interface and the deformation of both particle and substrate has been gleaned from inspection of splat morphologies, which also assists in assessing the likelihood that particle adhesion will lead to successful coating formation. SEM was used to examine numerous splats associated with each of the tested spray conditions, and three broad impact
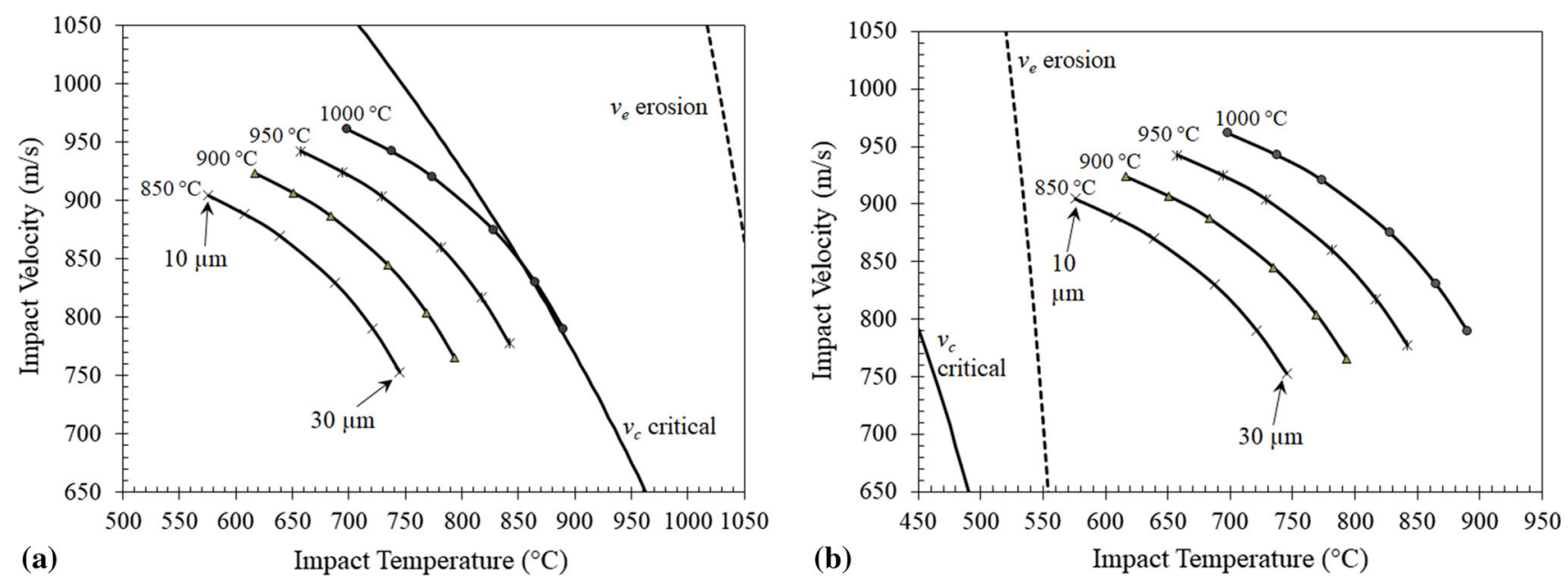

Fig. 8 Empirical study of desirable impact conditions for adhesion of SAM1651, with powder diameters of 10-30 $\mu \mathrm{m}$, gas pressure of 4 MPa, and gas temperatures of $850,900,950,1000{ }^{\circ} \mathrm{C}$, with (a) $\mathrm{T}_{\mathrm{s}}=\mathrm{T}_{\mathrm{m}}$; (b) $\mathrm{T}_{\mathrm{s}}=\mathrm{T}_{\mathrm{g}}$ 


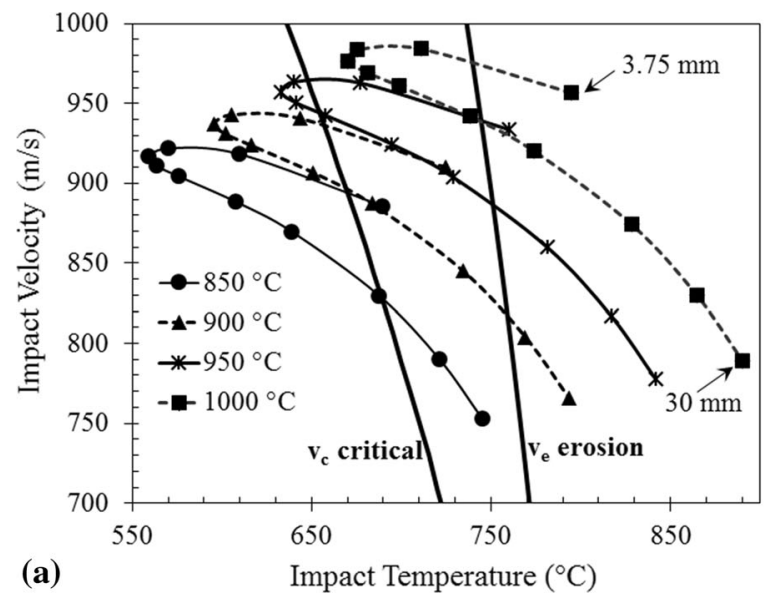

Fig. 9 (a) Empirically derived SAM1651 deposition window, bounded by $\mathrm{v}_{\mathrm{c}}$ and $\mathrm{v}_{\mathrm{e}}$, with $\mathrm{T}_{\mathrm{s}}=1.4 \mathrm{~T}_{\mathrm{g}}$, powder diameters of 3.75 $30 \mu \mathrm{m}$, gas pressure of $4 \mathrm{MPa}$, and gas temperatures of $850-1000{ }^{\circ} \mathrm{C}$ (Ref 28). (b) Experimentally observed fraction of adhered particle

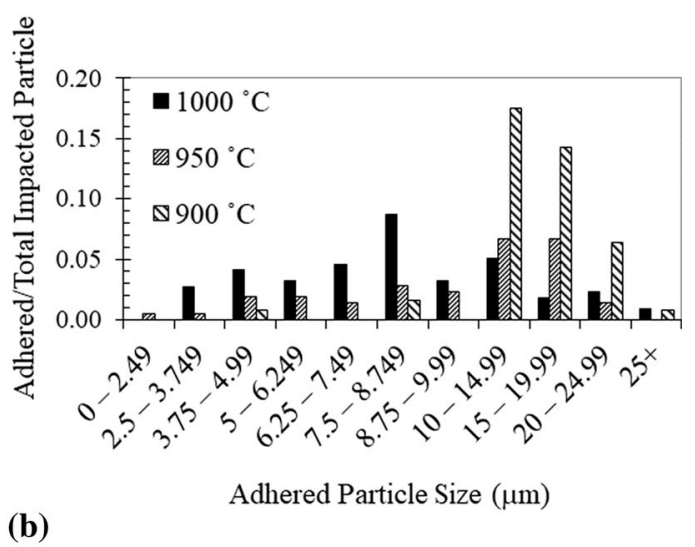

splats, with gas temperatures of 900,950 , and $1000{ }^{\circ} \mathrm{C}$ (gas pressure of $4 \mathrm{MPa}$ ). Variable bin sizes used to normalize the mean number of particles per bin

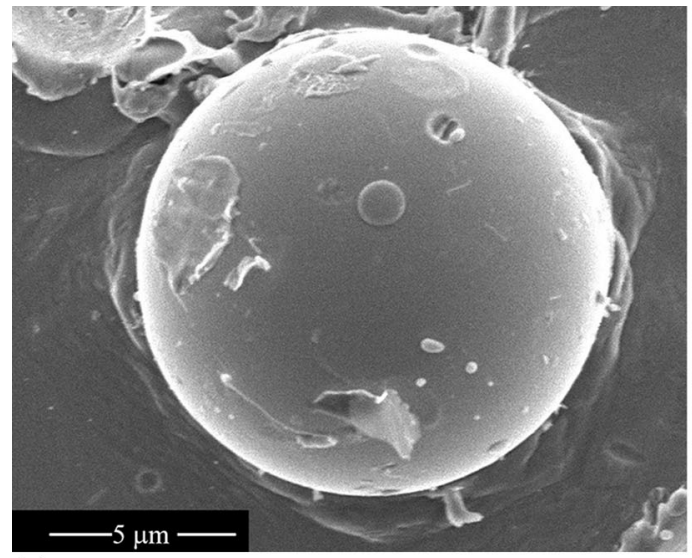

(a)

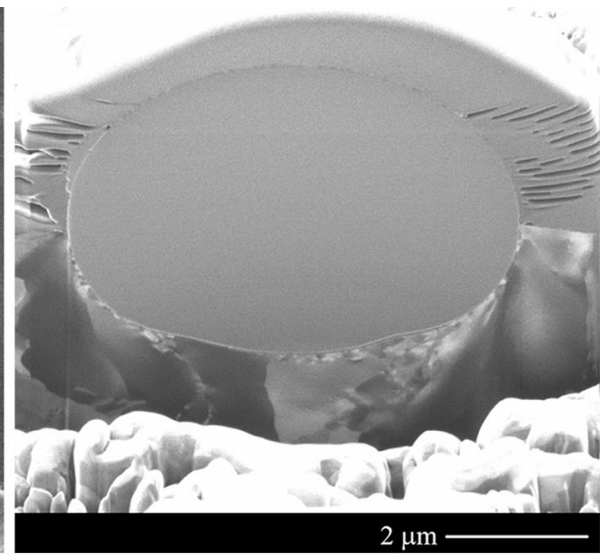

(b)

Fig. 10 SEM micrographs of deformed and adhered SAM 1651 particle splats: (a) top; (b) FIB sectioned

morphology types were revealed. This examination process and impact categorization is detailed and previously presented elsewhere (Ref 30 ). A brief summary is provided again here, to categorize impact morphologies as (1) deformed/adhered particles, (2) undeformed/adhered particles, and (3) substrate craters formed by rebounded particles.

Type 1 impacts are categorized by adhered metallic glass particles for which both particle and substrate display plastic deformation. Particles involved in this type of impact (Fig. 10) exhibit localized deformation and material jets on their surfaces, which suggest the occurrence of thermal softening along their boundaries. The softened region surrounding the rim of such particles appears to be approximately $1-2 \mu \mathrm{m}$ thick. It is believed that this softening results from the very high deformation rates associated with the impact event and the subsequent non-uniform stress distributions. The softened particle region suggests adiabatic shear instabilities by localized shear banding, which is believed to facilitate the formation of an intimate bond between the impacting metallic glass feedstock particles and the substrate surface. This is further explored by TEM inspection of the interface, as described below. Several particles of this type were sectioned using a focused ion beam and viewed in the SEM following the deposition of a platinum or carbon overlay (Ref 40). Cross sections revealed a more elliptical than spherical morphology, further suggesting plastic deformation of the particle, as well finer substrate microstructure at the interface than in regions farther from the impacted particle (Fig. 10b). This type of impact, indicative of thermal softening and good-quality particle/interface bonds, is believed to be favorable for the formation of particle/particle bonding and coating formation. 
SEM examination of specimens also revealed multiple examples of Type 2 impacts, in which particles adhered to the substrate but displayed very little plastic deformation. The morphologies in this case (Fig. 11) are indicative of a situation in which particle softening is not adequate due to impact temperatures being too low, but particle velocity exceeds the critical value and promotes adhesion through substrate deformation. Undeformed adhered particles are assisted by the deformation and flow of the crystalline substrate, as is evidenced by material jets at the outer edge of the impact craters (Fig. 11b). This suggests that shear instabilities are occurring primarily in the substrate material (Ref 36). In addition, adhered splat shapes appear more spherical than elliptical, further suggesting that particle deformation is predominantly elastic in these cases. Without proper softening, further secondary impacts are not expected to result in successful deposition as the particle/particle collision will result in powder fractures. In addition, gaps revealed at the particle/substrate interface indicate interrupted contact and suggest a low-quality bond with the substrate (Fig. 11c; Ref 30). This type of impact behavior is not conducive to the successful buildup of a thick cold-sprayed coating.

The third type of impact morphology found is that of empty craters resulting from rebounded particles. This occurs when rebound energy exceeds that of adhesion energy, and the crystalline substrate material is compressed by the impacting particle and flows to form a crater with raised edges around its rim (Fig. 12a), before rebounding. Impact conditions and particle size affect the competition between rebound and adhesion energies in this situation (Ref 41). Several craters were covered with a protective overlay of platinum, sectioned, and polished in the FIB. Figure 12(b) exhibits a representative elliptical crater with a flattened bottom. Distinctly smaller grains near the crater interface indicate a significant substrate deformation at the impact contact surface.

\section{Transmission Electron Microscopy}

In addition to the splat morphology characterization of deformed and FIB-sectioned particles, preliminary examination of particle/substrate bonds has been performed using scanning/transmission electron microscopy (S/TEM). Multiple locations along the particle/substrate interface were examined for two different particle splats prepared using a FIB (Fig. 13a). The selected particles, one sprayed at $800{ }^{\circ} \mathrm{C}$ and the other at $900{ }^{\circ} \mathrm{C}$, appeared (at relatively low magnification) to be deformed and bonded to the substrate and were categorized as morphology Type 1 .

Higher magnification revealed dark regions between the particles and the substrate at multiple locations along the interface, such as that seen as in Fig. 13(b). These regions are $\sim 10 \mathrm{~nm}$ or less in thickness. High-angle annular dark field (HAADF) STEM and energy-dispersive x-ray spectroscopy (EDS) analysis indicate that the dark regions at the splat/substrate interface correspond to an oxide layer (Fig. 13c), and in some cases, a very thin carbon layer $(\sim 2 \mathrm{~nm}$ ) between two oxide layers (Fig. 14). Associated EDS line scans, such as that seen in Fig. 15, indicate that the oxygen content is higher within the interface layer in these regions than within the adjacent substrate or the splat, and the carbon content (when present) is highest between the oxide layers. EDS maps also demonstrate the presence of yttrium within the oxide layer adjacent to the SAM1651 splat (Fig. 15c).

A thin native oxide is known to form on the polished mild steel substrate surface when exposed to ambient atmosphere (Ref 42), along with impurities such as amorphous carbon. TEM analysis of the interface locations with two oxide layers separated by a small gap filled with carbon suggests that the top yttrium-containing oxide layer on the splat surface appears amorphous, as does the carbon, while the bottom oxide layer on the substrate surface appears crystalline (Fig. 16).

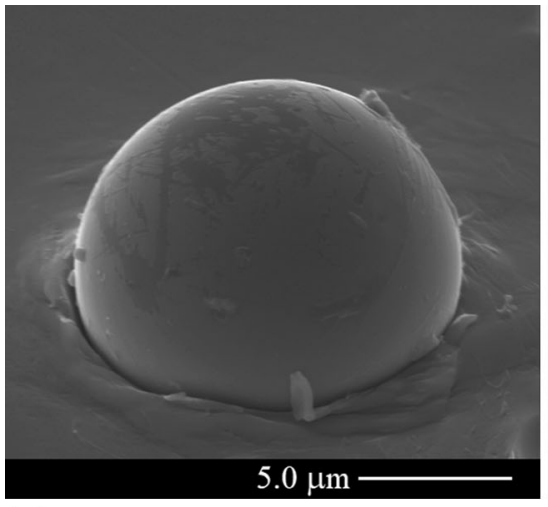

(a)

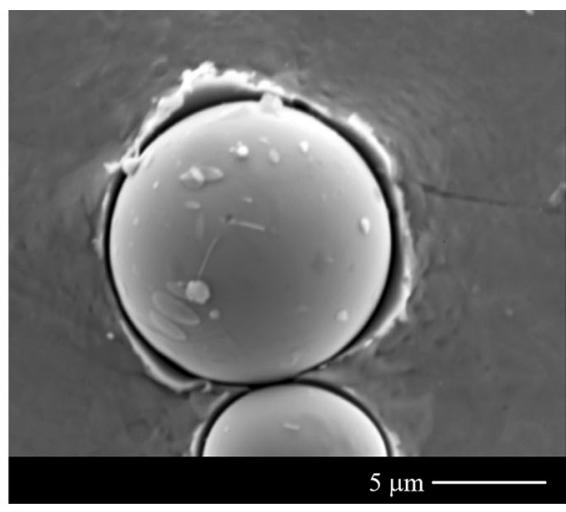

(b)

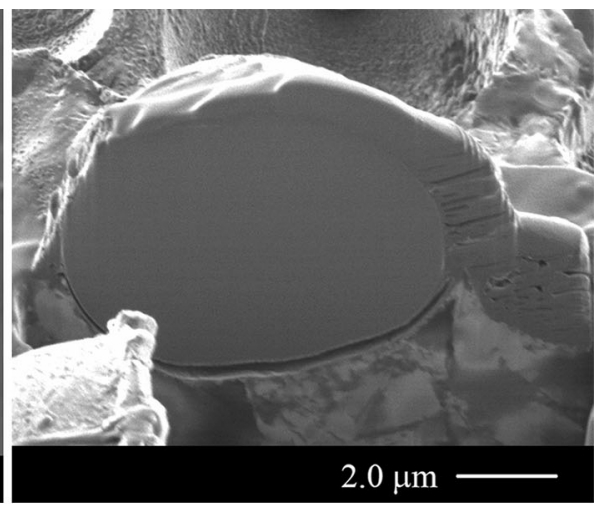

(c)

Fig. 11 SEM micrographs of adhered SAM1651 particle splats that display minimal plastic deformation: (a) tilt 50 ; (b) top view (tilt $0^{\circ}$ ); (c) FIB sectioned (Ref 30) 


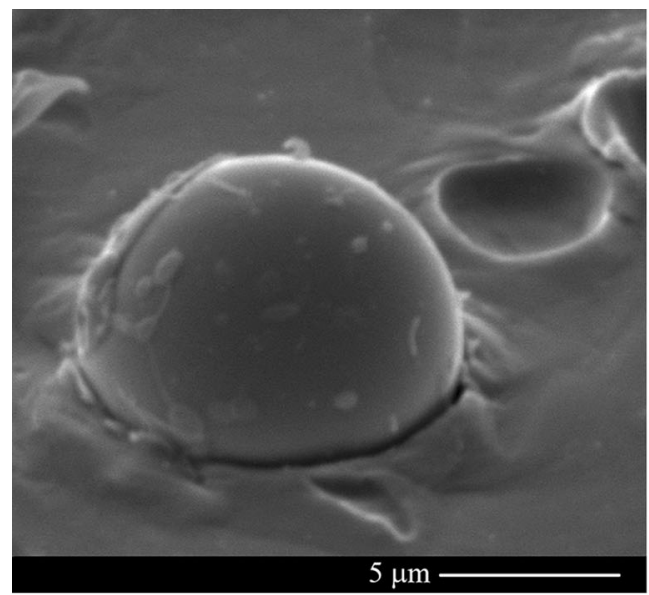

(a)

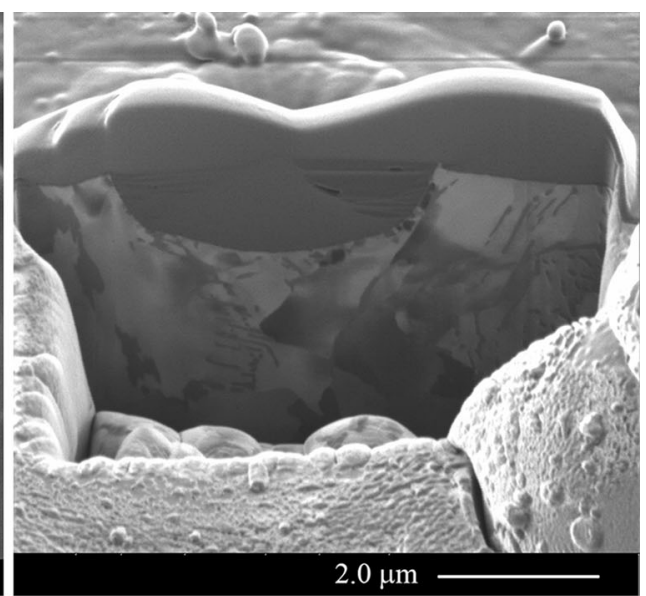

(b)

Fig. 12 SEM micrographs of rebound craters formed by impacting SAM 1651 particles: (a) beside an adhered particle (tilt 50 ${ }^{\circ}$ ); (b) FIBsectioned crater filled with platinum overlay

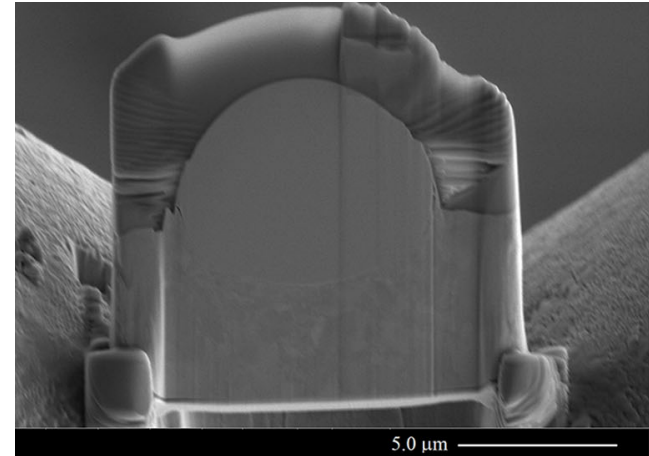

(a)

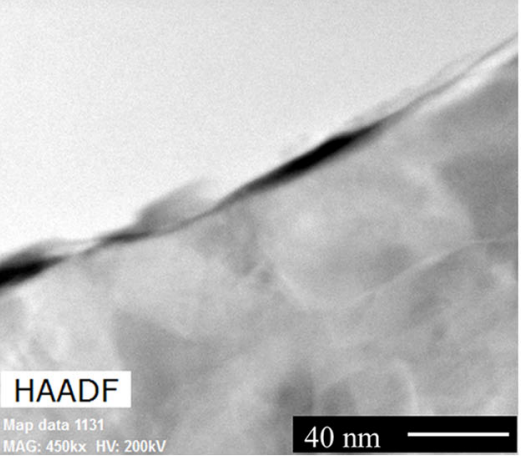

(b)

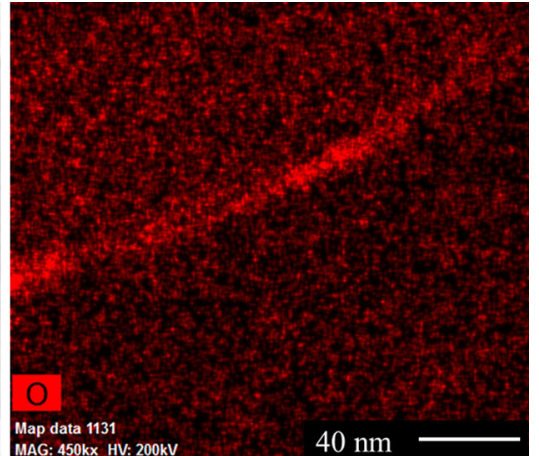

(c)

Fig. 13 (a) Thin section prepared by gallium ion milling; (b) cross-sectional TEM image of a location on the $800{ }^{\circ} \mathrm{C}$ particle/substrate interface; (c) HAADF-STEM/EDS of the same interface, oxygen map

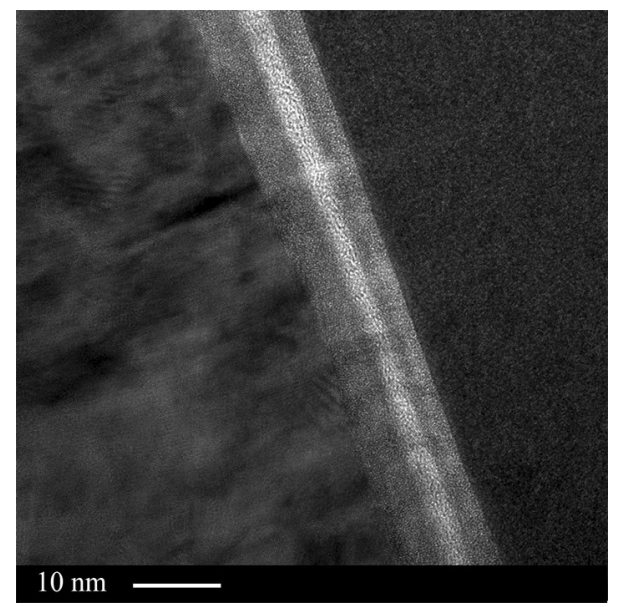

Fig. 14 Cross-sectional HRTEM image of splat/substrate interface with two distinct oxide layers and a carbon layer between them

Further investigation is necessary to establish whether the oxide layer revealed on the splats was present prior to deposition. Preliminary examination has included cross sectioning of as-received powder particles, which were first embedded in carbon paint, by broad ion beam milling (Leica EM TIC 3X). Line profiles (Fig. 17) collected to investigate the possible segregation of oxygen in the shell of the polished powder particles indicated oxygen enrichment on only 1 of 10 particles examined. These results may suggest that dynamic oxidation of SAM1651 particles occurs during cold spraying, but additional examination is needed. It is also likely that the preheating of the SAM1651 powder, done to raise the impact temperature of particles and beneficially lower the critical velocity and improve deposition efficiency (Ref 43), provides more opportunity for the development of an oxide layer during processing.

While it is generally recognized that solid-state bonding requires tight contact of clean metallic surfaces, and surface oxide layers on the particle and substrate must therefore be broken and removed during impact (Ref 42), recent research suggests that a nanoscale amorphous oxide film may remain along the particle/substrate interface of well- 


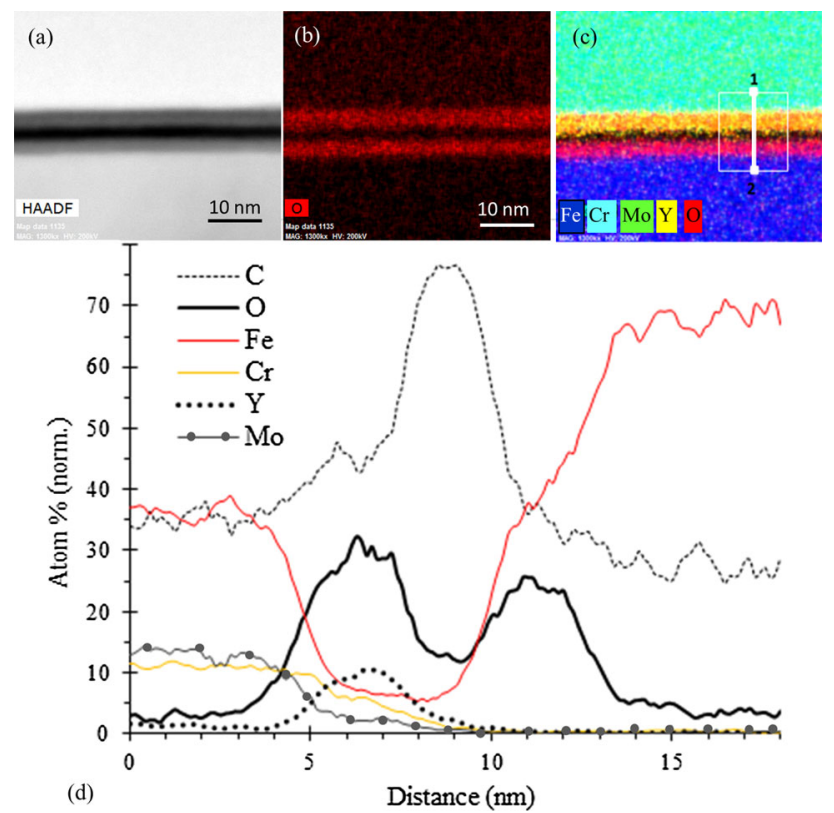

Fig. 15 Splat/substrate interface location with two oxide layers and a carbon layer between them (a) cross-sectional HRTEM image; (b) HAADF-STEM/EDS, elemental oxygen map; (c) HAADFSTEM/EDS, with elemental map of $\mathrm{Fe}, \mathrm{Cr}, \mathrm{Mo}, \mathrm{Y}$, and $\mathrm{O}$, and box-defining limits of line scan; (d) EDS line scan, from splat on top (\#1) to steel substrate below (\#2)

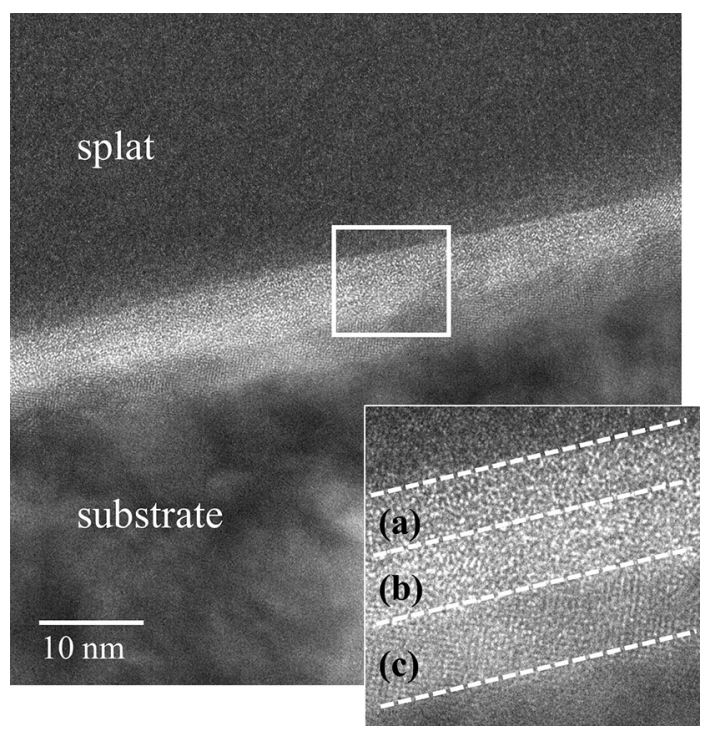

Fig. 16 HRTEM cross-sectional image of splat/substrate interface with two oxide layers and a carbon layer between them. (a) Oxide layer on splat surface appears amorphous; (b) amorphous carbon layer; (c) oxide layer on steel substrate appears crystalline

bonded regions (Ref 44). The TEM results in this study show evidence of an enhanced oxygen signal at the interface of what appear to be well-bonded or bridged locations along the interface between SAM1651 splats and the steel substrate. For example, the EDS oxygen maps in Fig. 13(c) and 18 suggest the presence of a thin oxide layer

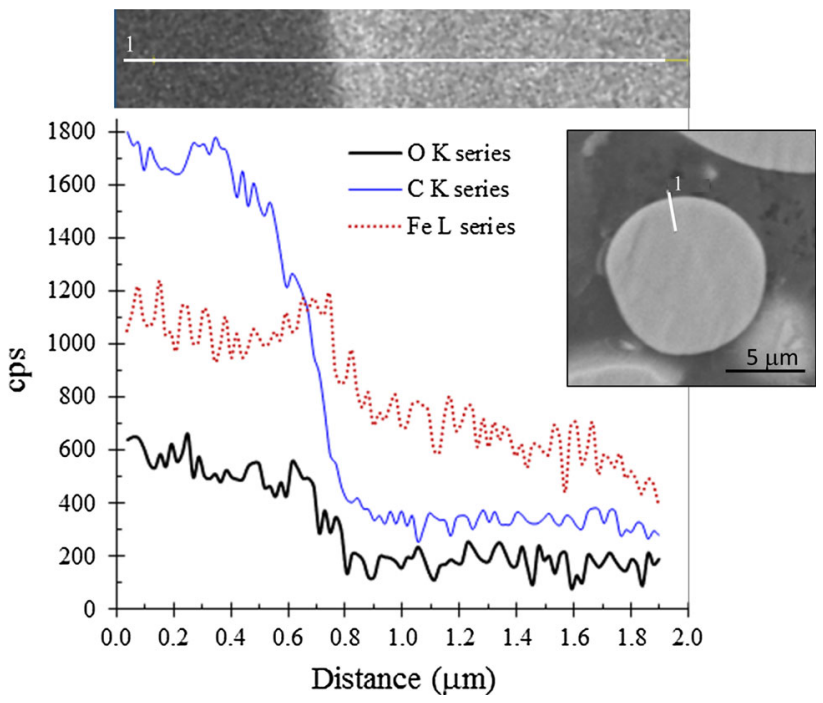

Fig. 17 SEM image of the milled surface of an as-received powder particle (insert) and the associated line scan extracted from the region indicated by the line, which starts away from the particle and crosses into the milled powder particle
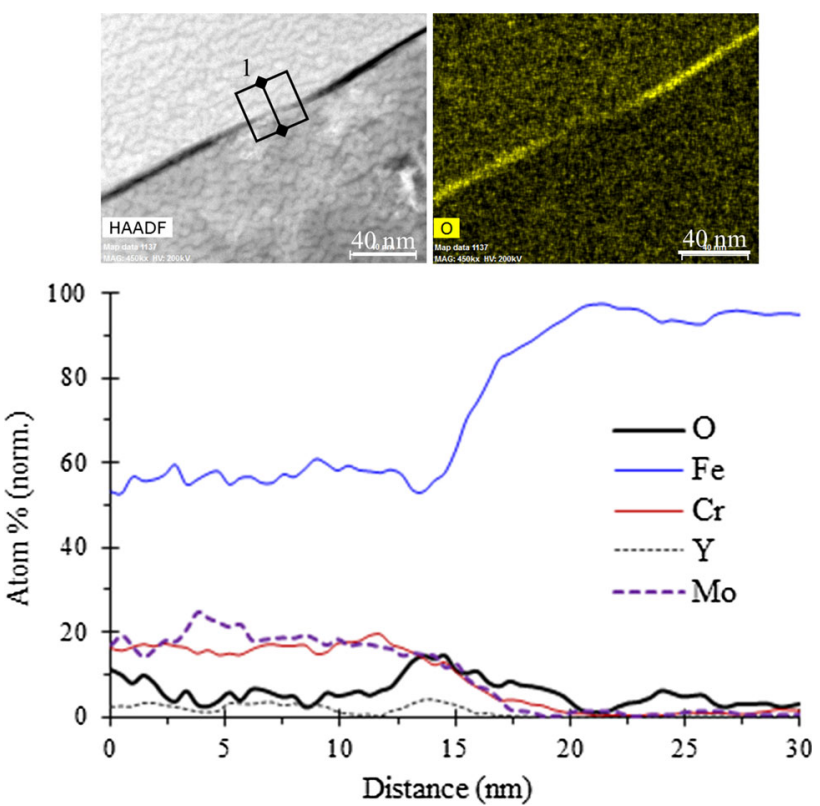

Fig. 18 Cross-sectional TEM image of a well-bonded region of the splat/substrate interface and associated HAADF-STEM/EDS elemental oxygen map. Line scan extracted from the region indicated by the box, starting with the splat on top (\#1) and progressing to the steel substrate below

at the particle substrate interface in these regions, possibly supporting the findings of Kim et al. (Ref 44). Additional TEM studies are necessary, however, to characterize the bonding mechanism for cold-sprayed Fe-based metallic glass and investigate the oxide layer(s) detected at the 
interface. Such work is planned in conjunction with full coating trials and subsequent coating characterization.

\section{Conclusions}

The results of this study demonstrate the necessity of controlling cold spray process parameters in an effort to achieve desired impact conditions and promote the coating formation of Fe-based metallic glass powders. Adequate thermal softening of the Fe-Cr-Mo-C-B-Y metallic glass powder particles is required to support their deformation upon impact with the steel substrate, but temperature must be regulated to also ensure that phase transformations, microstructural changes, and grain growth do not occur. In order to achieve this softening, both computational and experimental results indicate that cold-sprayed Fe-based amorphous powders must be heated to a temperature that is within the supercooled liquid region. Results also suggest that effective impact velocities for these powders are attainable using a nitrogen carrier gas at a pressure of $4 \mathrm{MPa}$.

The results of the single-impact splat studies validate the developed empirical model of temperature and velocity limits associated with successful particle adhesion. Particle deformation is improved by the use of a pre-heating chamber and subsequently higher impact temperatures, which vary on the basis of particle size and process gas temperature. Splat examination suggests that shear instabilities and plastic flow are enhanced above the glass transition temperature, which is useful as the basis for defining the appropriate reference temperature for the softening of SAM1651 alloy, determined to be $1.4 T_{\mathrm{g}}$. TEM studies suggest that the deformed and adhered particles characterized as favorable cold-sprayed impacts retain their amorphous structure, and hence, their superior properties. TEM results also provide evidence that a thin oxide layer is often present between a well-adhered particle and the substrate, suggesting that bonding is still feasible with an increased oxygen content in regions of the splat/substrate interface. These results are favorable with regard to the expected success of forming thick cold-sprayed SAM1651 coatings that remain amorphous.

This study provides evidence that the deposition of coldsprayed Fe-based amorphous coatings appears promising with the proper optimization of process parameters. Such coatings are expected to retain the exceptional properties of the feedstock powder, including exceptional hardness and wear and corrosion resistance. Full coating tests are currently planned to allow for the study of the coating/substrate bond and the detailed characterization of coating properties.
Acknowledgments The authors thank the following colleagues for their collaboration in various aspects of this project: Ozan Ozdemir (South Dakota School of Mines and Technology) for performing DSC and DTA; Xiaojun Gu (Bucknell University) for casting bulk ingots and performing compression testing; Donna Ebenstein (Bucknell University) for nanoindentation; Dennis Helfritch (TKC Global at Army Research Laboratory) for access to spray facilities. This work involved shared facilities supported in part by the Penn State MRSEC, Center for Nanoscale Science, under the NSF award DMR-1420620. The authors acknowledge support from Bucknell University through a Dean's Fellowship (Wright) and a Presidential Professorship (Ziemian).

Open Access This article is distributed under the terms of the Creative Commons Attribution 4.0 International License (http://crea tivecommons.org/licenses/by/4.0/), which permits unrestricted use, distribution, and reproduction in any medium, provided you give appropriate credit to the original author(s) and the source, provide a link to the Creative Commons license, and indicate if changes were made.

\section{References}

1. Z.P. Lu, C.T. Liu, J.R. Thompson, and W.D. Porter, Structural Amorphous Steels, Phys. Rev. Lett., 2004, 92(24), p 245503

2. S.J. Pang, T. Zhang, K. Asami, and A. Inoue, Synthesis of Fe-CrMo-C-B-P Bulk Metallic Glasses with High Corrosion Resistance, Acta Mater., 2002, 50(3), p 489-497

3. R. Babilas and R. Nowosielski, Iron-Based Bulk Amorphous Alloys, Arch. Mater. Sci. Eng., 2010, 44(1), p 5-27

4. K. Hildal, N. Sekido, and J.H. Perepezko, Critical Cooling Rate for Fe48Cr15Mo14Y2C15B6 Bulk Metallic Glass Formation, Intermetallics, 2006, 14, p 898-902

5. M.S. Bakare, K.T. Voisey, K. Chokethawai, and D.G. McCartney, Corrosion Behaviour of Crystalline and Amorphous Forms of the Glass Forming Alloy $\mathrm{Fe}_{43} \mathrm{Cr}_{16} \mathrm{Mo}_{16} \mathrm{C}_{15} \mathrm{~B}_{10}$, J. Alloys Compd., 2012, 527, p 210-218

6. A. Basu, A.N. Samant, S.P. Harimkar, J. Dutta Majumdar, I. Manna, and N.B. Dahotre, Laser Surface Coating of Fe-Cr-MoY-B-C Bulk Metallic Glass Composition on AISI, 4140 Steel, Surf. Coat. Technol., 2008, 202(12), p 2623-2631

7. Y.J. Huang, Y.Z. Guo, H.B. Fan, and J. Shen, Synthesis of Fe-CrMo-C-B Amorphous Coating with High Corrosion Resistance, Mater. Lett., 2012, 89, p 229-232

8. S. Katakam, S. Santhanakrishnan, and N.B. Dahotre, Fe-Based Amorphous Coatings on AISI, 4130 Structural Steel for Corrosion Resistance, JOM, 2012, 64(6), p 709-715

9. A. Kobayashi, S. Yano, H. Kimura, and A. Inoue, Fe-based Metallic Glass Coatings Produced by Smart Plasma Spraying Process, Mater. Sci. Eng., B, 2008, 148(1-3), p 110-113

10. W.H. Lu, Y.P. Wu, J.J. Zhang, S. Hong, J.F. Zhang, and G.Y. Li, Microstructure and Corrosion Resistance of Plasma Sprayed FeBased Alloy Coating as an Alternative to Hard Chromium, $J$. Therm. Spray Technol., 2011, 20(5), p 1063-1070

11. C. Zhang, L. Liu, K.C. Chan, Q. Chen, and C. Tang, Wear Behavior of HVOF-sprayed Fe-based Amorphous Coatings, Intermetallics, 2012, 29, p 80-85

12. S. Grigoriev, A. Okunkova, A. Sova, P. Bertrand, and I. Smurov, Cold Spraying: From Process Fundamentals Towards Advanced Applications, Surf. Coat. Technol., 2015, 268, p 77-84

13. A. Papyrin, V. Kosarev, S. Klinkov, A. Alkhimov, V. Fomin, High Velocity Interaction of Particles with the Substrate. Experiment and Modeling, Cold Spray Technology, 1st ed., Amsterdam, Elsevier Science, 2007, 2, 33-108. 
14. S. Yin, E. Ekoi, T. Lupton, D. Dowling, and R. Lupoi, Cold Spraying of WC-Co-Ni Coatings Using Porous WC-17Co Powders: Formation Mechanism, Microstructure Characterization and Tribological Performance, Mater. Des., 2017, 126, p 305-313

15. V. Bhattiprolu, K. Johnson, O. Ozdemir, and G. Crawford, Influence of Feedstock Powder and Cold Spray Processing Parameters on Microstructure and Mechanical Properties of Ti6Al-4 V Cold Spray Depositions, Surf. Coat. Technol., 2018, 335, $\mathrm{p} 1-12$

16. O. Nooirinah, A. Rohana, H.N. Nazrul, and M. Suhana, Supersonic Particle Deposition as Potential Corrosion Treatment Method for Helicopter Part in Malaysia, Int. J. Adv. Res. Eng. Technol., 2012, 3(2), p 275-279

17. W. Li, K. Yang, D. Zhang, X. Zhou, and X. Guo, Interface Behavior of Particles Upon Impacting During Cold Spraying of $\mathrm{Cu} / \mathrm{Ni} / \mathrm{Al}$ Mixture, Mater. Des., 2016, 95, p 237-246

18. P. Richer, M. Yandouzi, L. Beauvais, and B. Jodoin, Oxidation Behaviour of CoNiCrAlY Bond Coats Produced by Plasma, HVOF, and Cold Dynamic Spraying, Surf. Coat. Technol., 2010, 204(24), p 3962-3974

19. J.F. Löffler, Bulk Metallic Glasses, Intermetallics, 2003, 11(6), p 529-540

20. T. Schmidt, F. Gärtner, H. Assadi, and H. Kreye, Development of a Generalized Parameter Window for Cold Spray Deposition, Acta Mater., 2006, 54(3), p 729-742

21. F. Meng, S. Yue, and J. Song, Quantitative Prediction of Critical Velocity and Deposition Efficiency in Cold-Spray: A Finite-element Study, Scr. Mater., 2015, 107, p 83-87

22. J.W. Wu and H.Y. Fang, Critical and Maximum Velocities in Kinetic Spraying, Thermal Spray 2006: Building on 100 Years of Success, B.R. Marple, M.M. Hyland, Y.-C. Lau, R.S. Lima, and J. Voyer, Ed., ASM International, Seattle, 2006, p 396

23. V. Ponnambalam, S.J. Poon, and G.J. Shiflet, Fe-based Bulk Metallic Glasses with Diameter Thickness Larger Than One Centimeter, J. Mater. Res., 2004, 19(5), p 1320-1323

24. V.K. Champagne, D.J. Helfritch, S.P.G. Dinavahi, and P.F. Leyman, Theoretical and Experimental Particle Velocity in Cold Spray, J. Therm. Spray Technol., 2011, 20(3), p 425-431

25. D. Helfritch and V. Champagne, Optimal Particle Size for the Cold Spray Process, Thermal Spray 2006: Building on 100 Years of Success, B.R. Marple, M.M. Hyland, Y.-C. Lau, R.S. Lima, and J. Voyer, Ed., ASM International, Seattle, 2006, p 396

26. ANSYS Fluent User's Guide, Release 15, Canonsburg, PA, 2013

27. B. Andersson, R. Andersson, L. Håkansson, M. Mortensen, R. Sudiyo, and B. van Wachem, Computational Fluid Dynamics for Engineers, 1st ed., Cambridge University Press, Cambridge, 2012, p 202

28. D.E. Cipoletti, C.W. Ziemian, W.J. Wright, D.J. Helfritch, K.V. Haile, M.N. Okwara, and K.A. Hetherington, Critical Velocity Window for the Deposition of Iron-Based Metallic Glass Particles using Cold Spray, Thermal Spray 2015: Proceedings from the International Thermal Spray Conference, A. McDonald, A. Agarwal, G. Bolelli, A. Concustell, Y.-C. Lau, F.-L. Toma, E. Turunen, and C. Widener, Ed., May 11-14, 2015 (Long Beach, California, USA), ASM International, 2015, p 1225

29. Q. Chen, D. Zhang, J. Shen, H. Fan, and J. Sun, Effect of Yttrium on the Glass-Forming Ability of Fe-Cr-Mo-C-B bulk amorphous alloys, J. Alloys Compd., 2007, 427(1-2), p 190-193
30. C.W. Ziemian and W.J. Wright, An Experimental Study of Cold Sprayed Fe-Based Metallic Glass Powder Particles, Proceedings of 30th International Conference on Surface Modification Technologies (SMT30), June 29-July 1, 2016 (Milan, Italy)

31. W.L. Johnson and K. Samwer, A Universal Criterion for Plastic Yielding of Metallic Glasses with a $(\mathrm{T} / \mathrm{Tg})^{2 / 3}$ Temperature Dependence, Phys. Rev. Lett., 2005, 95(19), p 195501

32. H. Assadi, F. Gärtner, T. Stoltenhoff, and H. Kreye, Bonding Mechanism in Cold Gas Spraying, Acta Mater., 2003, 51, p 43794394

33. C.-J. Li, W.-Y. Li, and H. Liao, Examination of the Critical Velocity for Deposition of Particles in Cold Spraying, J. Therm. Spray Technol., 2006, 15(2), p 212-222

34. P. Richer, B. Jodoin, K. Taylor, E. Sansoucy, M. Johnson, and L. Ajdelsztajn, Effect of Particle Geometry and Substrate Preparation in Cold Spray, Thermal Spray 2005: Thermal Spray Connects: Explore Its Surfacing Potential!, E. Lugscheider, Ed., DVS-German Welding Society, Basel, 2005, p 193-198

35. C.W. Ziemian, M.M. Sharma, B.D. Bouffard, T. Nissley, and T.J. Eden, Effect of Substrate Surface Roughening and Cold Spray Coating on the Fatigue Life of AA2024 Specimens, Mater. Des., 2014, 54, p 212-221

36. T. Schmidt, H. Assadi, F. Gärtner, H. Richter, T. Stoltenhoff, H. Kreye, and T. Klassen, From Particle Acceleration to Impact and Bonding in Cold Spraying, J. Therm. Spray Technol., 2009, 18(5-6), p 794-808

37. G.R. Johnson and W.H. Cook, A Constitutive Model and Data for Metals Subjected to Large Strains, High Strain Rates and High Temperatures, Proceedings of the 7th International Symposium on Ballistics, April 19-21, 1983 (The Hague, Netherlands), 1983, pp 541-547.

38. C.R. Cao, D.W. Ding, D.Q. Zhao, E. Axinte, H.Y. Bai, and W.H. Wang, Correlation Between Glass Transition Temperature and Melting Temperature in Metallic Glasses, Mater. Des., 2014, 60, p 576-579

39. A. List, F. Gartner, T. Schmidt, and T. Klassen, Impact Conditions for Cold Spraying of Hard Metallic Glasses, J. Therm. Spray Technol., 2012, 21, p 531-540

40. L.A. Giannuzzi and F.A. Stevie, A Review of Focused Ion Beam Milling for TEM Specimen Preparation, Micron, 1999, 30(3), p 197-204

41. S. Yoon, C. Lee, H. Choi, H. Kim, and J. Bae, Impacting Behavior of Bulk Metallic Glass Powder at an Abnormally High Strain Rate During Kinetic Spraying, Mater. Sci. Eng. A, 2007, 449-451, p 911-915

42. A. Moridi, S.M. Hassani-Gangaraj, M. Guagliano, and M. Dao, Cold Spray Coating: Review of Material Systems and Future Perspectives, Surf. Eng., 2014, 36(6), p 369-395

43. K.-H. Kim and S. Kuroda, Amorphous Oxide Film Formed by Dynamic Oxidation During Kinetic Spraying of Titanium at High Temperature and Its Role in Subsequent Coating Formation, Scr. Mater., 2010, 63, p 215-218

44. K.-H. Kim, M. Watanabe, K. Mitsuishi, K. Iakoubovskii, and S. Kuroda, Impact Bonding and Rebounding Between Kinetically Sprayed Titanium Particle and Steel Substrate Revealed by HighResolution Electron Microscopy, J. Phys. D Appl. Phys., 2009, 42, p 065304 